\title{
Association between post-cessation weight gain and eating behavior changes
}

\author{
Ali Erman Killi, (1) Melike Mercan Baspinar, (1) Okcan Basat \\ Department of Family Medicine, University of Health Sciences, Gaziosmanpasa Taksim Teaching and Research Hospital, Istanbul, Turkey
}

\begin{abstract}
OBJECTIVE: Fear of post-cessation weight gain may be a barrier to cessation therapy or may lead to smoking relapse. This study aimed to evaluate the relationship between the change in eating behavior and post-cessation weight gain.

METHODS: A prospective study that included 103 cigarette smokers, who visited the family medicine clinics of a training and research hospital for smoking cessation treatment between June 2018 and December 2018, was planned. A face to face survey (including Turkish version of Dutch Eating Behaviour Questionnaire-DEBQ and weight measures) was applied to all individuals at first and the final visits for the assessment of restrained, emotional, and external eating behaviors. Statistical analyses were completed using the IBM SPSS Statistics 22 program.

RESULTS: Of 103 patients screened ( $M$ age $=38.3$ years $S D=9.28$ ), 58.3\% were male, and $40.8 \%$ were in heavy nicotine dependence level (NDL) group. The mean weight increased by $4.74 \pm 2.63 \mathrm{~kg}$ in three months of smoking cessation. In the high NDL group, three subscales score (restrained $p<0.001$, emotional $p=0.007$, external $p=0.005$ ) of the DEBQ increased. Weight gain was significative associated with NDL $(p=0.01)$. There was a positive correlation between Fagerstrom score and weight $(\mathrm{kg})$ gain ( $r: 0.34 ; p=0.001)$. Weight change according to the emotional eating behavior was significantly different by gender (female $p=0.005$; male $p=0.04$ ). Women had a higher difference in emotional eating behavior score than men. Obese smokers had a higher initial restrained eating score than non-obese smokers $(p=0.009)$. Weight gain of nicotine replacement therapy group had a similar result in the pharmacotherapy (varenicline) group $(p=0.26)$. Both of treatment types concluded with a significant weight change $(p=0.001)$.
\end{abstract}

CONCLUSION: This study obtained that post-cessation weight gain is related to high nicotine dependence, and quit smoking causes increased scores of emotional, restrained, external eating behavior subscales. Post-cessation eating behavior is negatively affected by quit smoking.

Keywords: Dutch eating behaviour questionnaire-DEBQ; eating behaviour; smoking cessation; weight gain.

Cite this article as: Killi AE, Mercan Baspinar M, Basat $O$. Association between post-cessation weight gain and eating behavior changes. North Clin Istanb 2020;7(2):153-160.

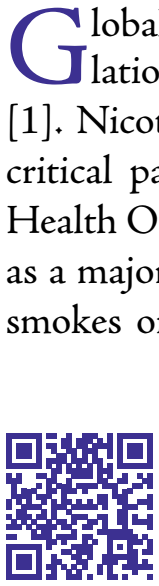

addiction is a public health problem causing the burden of chronic illness.

Even if smokers want to quit smoking, the unwanted consequences of quitting can be discouraging. Weight gain is one of the disadvantages of smoking cessation. It is a widely-held concern of both the public at large and health professionals $[3,4]$. It is not probable to negate the

Received: September 12, 2019 Accepted: November 09, 2019 Online: December 02, 2019

Correspondence: Dr. Melike MERCAN BASPINAR. Saglik Bilimleri Universitesi, Gaziosmanpasa Taksim Egitim ve Arastirma Hastanesi, Aile Hekimligi Anabilim Dali, Istanbul, Turkey.

Tel: +90 2129453000 e-mail: drmelikemercan@gmail.com

(c) Copyright 2020 by Istanbul Provincial Directorate of Health - Available online at www.northclinist.com 
health benefits of quit smoking, but its cosmetic effects may prevent attempts to cessation [4]. Fear of weight gain may be a negative side effect or may lead to loss of motivation and cause relapse [5, 6]. Findings showed that cessation might be related to a greater fear of weight gain among lean women. Similarly, another cohort study found in both sexes a positive relationship between BMI and smoking cessation [7]. On the other hand, another study defined that among former smoking women, the data did not show higher odds of overweight or obesity than among female never smokers [8].

Although the anorectic or hunger effects of nicotine has not been proved, nicotine reduces food consumption and raises basal metabolic rate [9]. Nicotine addicts may be at higher risk of hyperthyroidism more than nonsmokers, which may increase metabolic rate [10]. Weight change after quitting is with around $16 \%$ losing weight while $13 \%$ gain more than $10 \mathrm{~kg}$ and weight gain mechanism is not predictable. Time in the first three months of cessation is the highest period of the rating of weight gain [11].

This present study aimed to define the relationship between eating behavior change and post-cessation weight change in nicotine addicts. We hypothesized that the negative effects of post-cessation eating behavior causes weight gain and may predict with the DEBQ scale in the clinic.

\section{MATERIALS AND METHODS}

\section{Participants}

This was a prospective study that included 103 cigarette smokers successfully achieved smoking abstinence. Clinical and demographic information on patients seen at family medicine clinics of a teaching and research hospital for smoking cessation therapy were supplied from face to face survey, including DEBQ and FTND scales. The patients were followed on their first visit and 4, 8, and 12 weeks after that and treated with nicotine replacement therapy (nicotine patch/gum) or varenicline.

\section{Selection Criteria}

All patients who met the following inclusion criteria were involved in this study:

- 18 years of age and older smokers who applied for smoking cessation treatment

- To take cessation treatment between June 15, 2018 and December 15, 2018

- To succeed in treatment and no smoking for three months during therapy.

Patients were excluded from this study if the patients had:

- An active psychiatric disease

- Prior diagnosis of any eating disorders

- Bariatric surgery history

- Received or recommended medical nutrition therapy or diet

- Any other substance abuse

\section{Measures}

Weight: A digital platform scale was used to measure body weight.

Body Mass Index (BMI): The formula of $\mathrm{kg} / \mathrm{m} 2$ [weight/(height)2] was used to calculate BMI. Participants were categorized according to initial BMI (nonobese: $<30 \mathrm{~kg} / \mathrm{m}^{2}$ and obese $: \geq 30.0 \mathrm{~kg} / \mathrm{m}^{2}$ ).

Dutch Eating Behavior Questionnaire (DEBQ): DEBQ is a 33-item self-report measure with three scales: measuring external eating (externality), emotional eating (emotionality) and restrained eating behavior (restraint) [12]. Emotional eating is a response that shows a tendency towards overeating into the negative emotions, and it was detected that binge eating itself could also be related to emotional eating [13]. Externality means "external eating," which is eating in response to food-induced stimuli although there is no real internal state of hunger or satiety. Individuals may react to being overweight by intentionally restricting food intake irrespective of whether they are emotional or external eaters. Eating less than desired is the very nature of restrained eating behavior [14]. Turkish version of the DEBQ was assessed in three subscales similarly. The first ten questions were restrictive eating subscale. $11^{\text {th }}-23^{\text {th }}$ questions were emotional eating subscale, and $24^{\text {th }}-33^{\text {th }}$ questions were external eating subscale. The factorial validity and the reliability of the Turkish version of the DEBQ indicated the presence of three factors (emotionality, externality and restraint) with loadings similar to those of the original scale $[14,15]$.

Fagerstrom Test for Nicotine Dependence (FTND): Fagerstrom Test for Nicotine Dependence (FTND) is used for the evaluation of nicotine dependence level. Reliability in the Turkish version and factor analysis 
was done in 2004 by Uysal et al. [16]. Nicotine dependence was classified as mild ( $0-3$ points), medium (4-7 points), and heavy ( $8-10$ points) dependence groups.

\section{Ethical Approval and Consent to Participate}

The voluntary patients were informed about the questionary. The survey included a patient consent form on its first page. The Taksim Training and Research Hospital Clinical Research Ethics Committee reviewed and approved this study on date 13/06/2018 (Approval no: 68).

\section{Statistical Analysis}

Data were presented as mean $\pm \mathrm{SD}$ or $\mathrm{n}(\%)$. P-values determined for normally distributed parameters by paired samples t-test, student t-test, one-way ANOVA test and for non- normally distributed parameters by MannWhitney $\mathrm{U}$ test, Wilcoxon sign test, Kruskal Wallis test. Correlation analyses were used to investigate [1] weight gain and the change of initial-final DEBQ subscales, [2] initial BMI and initial DEBQ subscales and [3] final BMI and final DEBQ subscales. As a result of the power analysis before, of 97 successful patients on treatment, were planned to collect. Statistical analysis was completed using IBM SPSS Statistics 22 (SPSS IBM, Turkey) programs.

\section{RESULTS}

One hundred three patients ( $M$ age $=38.3$ years $\mathrm{SD}=9.28$ ) observed for smoking cessation treatment were enrolled in this study. The majority of them was male $(58.3 \%)$. The mean weight increased by $4.74 \pm 2.63$ $\mathrm{kg}$ at three months of smoking cessation. The average first DEBQ-Restrained eating, DEBQ-Emotional eating and DEBQ-External eating scores were 23.54 \pm 7.6 , $22.07 \pm 9.57,29.06 \pm 6.96$, respectively. $40.8 \%$ were in heavy, $53.4 \%$ were in moderate nicotine dependence level (NDL) group. The average smoking consumption was $23.0 \pm 13.24$ packet/years. The demographic data and smoking characteristics are shown in Table 1.

When we compared the data before and after smoking cessation, this study has detected that BMI $(\mathrm{p}<0.001)$, weight $(\mathrm{kg})(\mathrm{p}<0.001)$, restrictive eating behavior score $(\mathrm{p}<0.001)$, emotional eating behavior score $(\mathrm{p}=0.001)$ and external eating behavior score $(p=0.001)$ changed significantly after quitting smoke (analyzed by Wilcoxon signed ranks test). Weight gain and daily cigarette consumption (per day) were correlated positively $(r=0.297$
TABLE 1. Baseline characteristics $(n=103)$

\begin{tabular}{|c|c|c|c|}
\hline Personal characteristics & Range & $n(\%)$ & Mean \pm SD \\
\hline \multicolumn{4}{|l|}{ Gender } \\
\hline Female & & $43(41.7)$ & \\
\hline Male & & $60(58.3)$ & \\
\hline Age (years) & $22-64$ & & $38.3 \pm 9.28$ \\
\hline Height (cm) & $150-187$ & & $168.62 \pm 9.46$ \\
\hline \multicolumn{4}{|l|}{ Weight (kg) } \\
\hline First & $45-107$ & & $74.5 \pm 13.7$ \\
\hline Last & $50-113$ & & $79 \pm 13.76$ \\
\hline \multicolumn{4}{|l|}{ Weight change } \\
\hline BMI $\left(\mathrm{kg} / \mathrm{m}^{2}\right)$ & $0-14$ & & $4.74 \pm 2.63$ \\
\hline First & $17.3-38.3$ & & $26.11 \pm 4.2$ \\
\hline Last & $19.1-41.1$ & & $27.72 \pm 4.2$ \\
\hline Cigarettes per day & $5-80$ & & $26.07 \pm 11.11$ \\
\hline Cigarettes packet/year & $2-50$ & & $23.02 \pm 13.24$ \\
\hline Duration of smoking (years) & $2-50$ & & $21.3 \pm 10$ \\
\hline Smoking initiation age & $10-36$ & & $17 \pm 4.39$ \\
\hline \multicolumn{4}{|l|}{ FTND score } \\
\hline \multicolumn{4}{|l|}{$\begin{array}{l}\text { Nicotine dependence } \\
\text { level }\end{array}$} \\
\hline Mild & & $6(5.8)$ & \\
\hline Moderate & & $55(53.4)$ & \\
\hline High & & $42(40.8)$ & \\
\hline \multicolumn{4}{|l|}{ Therapy type } \\
\hline Varenicline & & $87(84.5)$ & \\
\hline \multicolumn{4}{|l|}{ Nicotine replacement } \\
\hline \multicolumn{4}{|l|}{ DEBQ- Restrained eating } \\
\hline First score & $10-43$ & & $23.54 \pm 7.6$ \\
\hline Last score & $10-47$ & & $26.72 \pm 8.34$ \\
\hline \multicolumn{4}{|l|}{ DEBQ- Emotional eating } \\
\hline First score & $13-58$ & & $22.07 \pm 9.57$ \\
\hline Last score & $13-58$ & & $25.11 \pm 11.14$ \\
\hline \multicolumn{4}{|l|}{ DEBQ- External eating } \\
\hline First score & $10-44$ & & $26.69 \pm 6.15$ \\
\hline Last score & $16-47$ & & $29.06 \pm 6.96$ \\
\hline
\end{tabular}

SD: Standard deviation; BMI: Body mass index; FTND: Fagerstrom Test for Nicotine Dependence; DEBQ; Dutch eating behavior questionnaire.

$\mathrm{p}=0.002)$. There was no association between the amount of weight $(\mathrm{kg})$ and lifetime cigarette (packet/years) consumption $(\mathrm{r}:-0.015 \mathrm{p}=0.88)$. No difference was detected between gender and weight gain. There was a positive correlation between Fagerstrom score and weight gain $(r=0.335 ; p=0.001)$. 
TABLE2. Assessment of eating behavior and weight gain according to the nicotine dependence level

Variables

FTND -Nicotine Dependence level

$\mathrm{p}$

\begin{tabular}{ccc}
\hline Mild & Moderate & Heavy \\
Mean \pm SD (Median) & Mean \pm SD (Median) & Mean \pm SD (Median)
\end{tabular}

\begin{tabular}{|c|c|c|c|c|}
\hline \multicolumn{5}{|l|}{ DEBQ-Restrained eating } \\
\hline First score & $23.67 \pm 4.76$ & $25.15 \pm 7.32$ & $21.43 \pm 7.9$ & ${ }^{1 \mathrm{a}} 0.06$ \\
\hline Last score & $29.33 \pm 4.76$ & $26.96 \pm 8.45$ & $26.02 \pm 8.63$ & ${ }^{1 \mathrm{a}} 0.63$ \\
\hline First-Last change $p$-value ${ }^{2 a}$ & $0.04 *$ & 0.09 & $<0.001$ & \\
\hline \multicolumn{5}{|l|}{ DEBQ-Emotional eating } \\
\hline First score & $22.67 \pm 10.01(21)$ & $23.56 \pm 10.99(19)$ & $20.02 \pm 7.02(17)$ & ${ }^{1 \mathrm{~b}} 0.52$ \\
\hline Last score & $23.67 \pm 10.31(21)$ & $25.87 \pm 11.87(22)$ & $24.31 \pm 10.41(21)$ & ${ }^{1 \mathrm{~b}} 0.85$ \\
\hline \multicolumn{5}{|l|}{ DEBQ-External eating } \\
\hline First score & $29.67 \pm 4.59$ & $26.64 \pm 6.6$ & $26.33 \pm 5.71$ & ${ }^{1 a} 0.46$ \\
\hline Last score & $31.67 \pm 4.18$ & $28.36 \pm 6.18$ & $29.6 \pm 8.13$ & ${ }^{1 a} 0.44$ \\
\hline First-Last change $p$-value ${ }^{2 a}$ & 0.47 & 0.09 & $0.005 *$ & \\
\hline \multicolumn{5}{|l|}{ Weight gain } \\
\hline Weight change $p$-value ${ }^{2 a}$ & $0.002 *$ & $<0.001$ & $<0.001$ & \\
\hline
\end{tabular}

SD: Standard deviation; DEBQ; Dutch eating behavior questionnaire. ${ }^{1 a}$ Oneway ANOVA test; ${ }^{1 b}$ Kruskal Wallis test; ${ }^{2 a P a i r e d}$ samples t-test; ${ }^{2 b}$ Wilcoxon sign test; ${ }^{*} \mathrm{p}$ value $<0.05$.

Post cessation weight change was significant between NDL groups $(p=0.01)$. The increase of final weight in high addiction compared to the first weight was found to be statistically significantly higher than those with low and moderate addiction levels $(\mathrm{p}=0.02 ; \mathrm{p}=0.01)$. Fagerstrom nicotine dependence is low, moderate and high in those; an increase in the last weight values compared to the initial weight values is statistically significant $(\mathrm{p}=0.002, \mathrm{p}<0.001, \mathrm{p}<0.001$ respectively). The assessment data on eating behavior scales and weight gain in nicotine addiction are shown in Table 2.

In this study, $18.4 \%$ of cases had a higher BMI than $30 \mathrm{~kg} / \mathrm{m}^{2}$ (obese). At the beginning of the study, obese smokers had a higher restrained eating score than nonobese smokers (restrained eating $p=0.009$, emotional eating $p=0.57$ and external eating $p=0.90)$. At the end of this study, no difference in eating behavior subscales was defined between obese and non-obese smokers, but all scores had increased, and change in restrained eating score was lower $(p=0.21)$ in obese smokers than non- obese smokers. When the groups were compared regarding mean weight gain, there was no difference $(p=0.23)$ although the mean weight gain in non-obese smokers was higher than obese smokers $(4.9 \pm 2.50 \mathrm{~kg} ; 4.0 \pm 3.13$ $\mathrm{kg}$, respectively).

In participants, positive correlations were detected between the first restraint and emotionality scores $(r=0.298$; $p=0.002$ ), between the first emotionality and externality scores $(r=0.227 ; p=0.02)$, and between the last emotionality and externality scores $(r=0.471 ; p<0.001)$.

The treatment type was nicotine replacement and varenicline; increase in the last weight values compared to the first weight values was statistically significant $(\mathrm{p}<0.001, \mathrm{p}<0.001$, respectively), but no statistically significant difference was obtained between the types of treatment in terms. Evaluation of the effects of smoking cessation treatment type is shown in Table 3.

The scores of the three subscales of the eating behavior questionnaire significantly increased in patients with high NDL (restrictive eating behavior $p<0,001$; 
TABLE 3. Evaluation of the effects of smoking cessation treatment type on weight gain

\begin{tabular}{lccc} 
Weight & NRT & $\begin{array}{c}\text { Pharmacotherapy } \\
\text { (Varenicline) } \\
\text { Mean } \pm \text { SD }\end{array}$ & $\mathrm{p}$ \\
& Mean \pm SD & & \\
& & & \\
& & & \\
First weight & $69.75 \pm 15.07$ & $75.37 \pm 13.34$ & ${ }^{\mathbf{1 a}} \mathbf{0 . 1 3}$ \\
Last weight & $75.56 \pm 16.34$ & $79.63 \pm 13.24$ & ${ }^{\mathbf{1 a}} \mathbf{0 . 2 8}$ \\
Weight change & $5.81 \pm 3.67$ & $4.54 \pm 2.37$ & $\mathbf{1 b}^{\mathbf{b}} \mathbf{0 . 2 6}$ \\
First-Last p-value $^{2 \mathrm{a}}$ & $<\mathbf{0 . 0 0 1 *}$ & $<\mathbf{0 . 0 0 1 *}$ & \\
\hline
\end{tabular}

NRT: Nicotine Replacement Therapy; SD: Standard deviation; ${ }^{1 a}$ Student t-test; ${ }^{1 b}$ Mann-Whitney U test; ${ }^{2 a}$ Paired samples t-test; ${ }^{*} \mathrm{p}<0.05$.

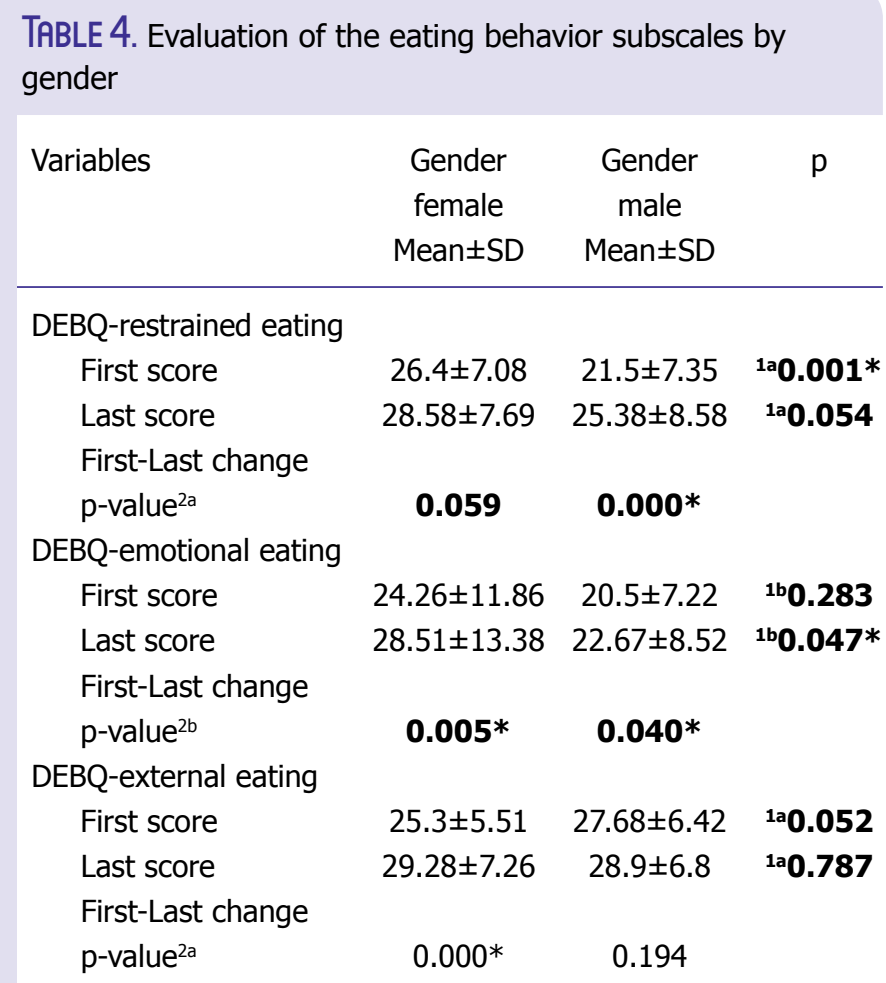

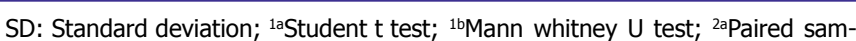
ples obese; ${ }^{2 b}$ Wilcoxon sign test; ${ }^{*} \mathrm{p}<0.05$.

emotional eating behavior $\mathrm{p}=0.007$; external eating behavior $\mathrm{p}=0.005)$. In low and high NDL groups, increase in the last restrictive eating averages was statistically significant compared to the first restrictive eating averages $(\mathrm{p}=0.04, p<0.001$, respectively). In moderate and high NDL groups, an increase in emotional eating scores was statistically significant $(p=0.03, p=0.007$, respectively). In those with high NDL, the increase in external eating averages was statistically significant $(p=0.005)$.
The increase in the last emotional eating scores of women and men compared to the average of the first emotional eating scores was significant $(p=0.005$; $p=0.04$, respectively). Evaluation of the subscales by gender is shown in Table 4.

\section{DISCUSSION}

In this prospective study conducted at a teaching and research hospital, we demonstrated that mean weight has increased by $4.74 \pm 2.63 \mathrm{~kg}$ at three months of smoking cessation, especially change in high nicotine dependence group was higher than others. Weight gain was a negative result of quit smoking as may be expected with high scores of DEBQ. This is similar to the results seen in a meta-analysis that lends support to weight gain after abstinence and shows a considerable variation in weight change, with $13 \%$ of quitters gaining weight more than $10 \mathrm{~kg}$ [11]. Smoking cessation period is associated with a mean increase of $4-5 \mathrm{~kg}$ in body weight during the first 12 months of abstinence, with most weight gain emerged within three months [11]. In a Czech study, smokers gain a mean of $5 \mathrm{~kg}$ post one year of cessation [17]. In a japan study, the mean BMI significantly $(p<0.001)$ increased from $23.5 \pm 3.6 \mathrm{~kg} / \mathrm{m}^{2}$ at the first visit to $23.9 \pm 3.8 \mathrm{~kg} / \mathrm{m}^{2}$ at three months following the first visit of cessation therapy [18]. Mean BMI of our study significantly $(\mathrm{p}<0.001)$ increased from $26.11 \pm 4.2$ $\mathrm{kg} / \mathrm{m}^{2}$ to $27.72 \pm 4.2 \mathrm{~kg} / \mathrm{m}^{2}$, too.

The more cigarettes they smoke, the more they can gain weight after quitting. But how long time? Cigarettes' daily consumption or cigarettes lifetime consumption?

In a previous study, the determinants of nicotine addicts who gained weight included volunteers smoking high numbers of cigarettes per day, African-American race, and young persons [4]. In this study, weight gain $(\mathrm{kg})$ and daily cigarette consumption (cigarette/per day) were related positively, but there was no relationship between the amount of weight $(\mathrm{kg})$ and the amount of lifetime cigarette consumption (packet/years).

Is there any difference in weight change according to gender? Being a male smoker or being a female smoker? May high nicotine dependence level a predictor for a woman's or man's cosmetic appearance after quit smoking? Maybe those who gain weight are always overweight?

Smokers with a higher nicotine dependence gain more weight [17]. In a sample of study conducted on United States (US) men, age-adjusted BMI was 25.3 
in nonsmokers and 24.7, 24.7, and 26.2 in light $(<20$ cigarettes/d), moderate (20-40 cigarettes/d), and heavy (>40 cigarettes/d) smokers, respectively $[19,20]$. In a study conducted in Germany, heavy smokers in the male gender were more prone to be obese than light smokers. Daily consumption of cigarettes (per day) was positively associated with being overweight and more so to obesity among former smoking men, but not for gender female $[8,20]$. A study conducted in Japan screened out that smokers with a high FTND score are more likely to gain weight during cessation therapy. Thus, heavy nicotine addicts may require a preventive approach to weight gain in the clinic [18]. In our study, median weight change in the high NDL was $5 \mathrm{~kg}$ while it was $4 \mathrm{~kg}$ in moderate NDL and $3 \mathrm{~kg}$ in mild NDL.

A nicotine addict always has an excuse for smoking another cigarette with one more cup of coffee. Maybe, for this reason, smoking cessation strategies should aim to prevent excuses for smoking, but all treatments have been focus on blocking the reward system or nicotine replacement.

Also of interest in our study is the association between treatment types and weight gain; a few studies show a difference between pharmacotherapy and nicotine replacement therapy. Lower BMI was indirectly related to eating less when stressed in smokers and, higher BMI was associated with non-smokers through eating more when stressed [19]. Current smokers tend to have a lower BMI than nonsmokers because of both nicotineinduced increases in energy expenditure and decreases in appetite [20]. A higher weight gain was related to a lower $\mathrm{BMI}$ and an increase in appetite at three months of cessation, but taking nicotine replacement therapy was associated with less weight gain at a 1-year follow-up [10]. Especially nicotine gum seems to be effective in delaying weight gain as a nicotine replacement therapy. In a group of female nicotine addicts who failed on cessation therapy because of weight gain, a dietary prescription (intermittent very-low-calorie diet) plus nicotine gum showed to both increase the success rate of smoking cessation and prevent weight gain. Otherwise, final weight gain was lower in the patients receiving bupropion or bupropion plus nicotine patch, compared with placebo, significantly [21]. Suppression on weight-gain has been explained by nicotine effects as a decrease in appetite and an increase in basal metabolism [22]. Another study showed that there was no difference between the nicotine patch and varenicline therapy groups according to BMI change [18]. In our study, although no statistically significant difference was obtained between the types of treatments in terms, both varenicline and nicotine replacement therapies resulted in weight gain, especially the average weight gain in the NRT group was higher than the pharmacotherapy group. Varenicline use was $84.5 \%$, and NRT use was $15.5 \%$ of the cases. Hence, this result could depend on the distribution of treatment type.

In the last two decades, the increase in the emotionality of eating has not been equaled with a similar high increase in the externality of eating behavior. We may look from an emotional perspective to the global obesity epidemic [23]. A study showed a positive relationship between externality and BMI and that it was gender-dependent [12]. In another study, both restraint and emotionality of eating behaviors moderated the evaluation between overconsumption and overweight. There was no positive or moderator effect on the externality of eating behavior. It was finalized that dietary restraint might prevent people who overeat from getting overweight. The final body weight may be determined more by people's tendency through emotionality of eating than by people's sensitivity to environmental food cues [23]. In our study, emotionality significantly changed in both groups, while changes were detected in female externality and male restraint.

At the beginning of this study, the emotionality score of the participants was positively associated with both externality and restraint. However, only the correlation between emotionality and externality of eating behavior increased while any other correlation was not obtained at the end.

The emotional eating behavior has a tendency towards overeating in response to negative emotions. It is prevalent in people who have obesity, women with eating disorders, and people who have a healthy weight but are on a diet [13]. In our study, no difference in the emotionality of eating behavior was obtained between obese and non-obese groups, but women had a more significant change in emotionality.

A study showed that higher body weight and size predicted higher restraint scores rather than the other way round during the 7-year follow-up [24]. Another study suggested that the abstaining smokers consumed more calories intake than smokers. Food intake was related to the urge to smoke, the urge to eat, and craving for a cigarette; and that eating could reduce the desire to smoke. These results were only apparent in female smokers. Additionally, restraint predicted increases in post-cessation 
food intake [25]. In a present study, there was no difference in weight change, the number of attempts to quit, and intentions to quit in six months between the restrained and unrestrained eaters. Endorsement for body weight control, the role of weight gain in experiences of smoking relapse, intentions to post-cessation weight loss, and intentions to quit in five years were significantly higher in restrained eaters more than unrestrained eaters [26].

In today's society, advertising stands/promotions meet us anywhere at any time. There is no doubt about the impacts of the advertising sector in the field of food marketing and the effects on eating behavior. "Would you like to buy a crema coffee and a donut gift for yourself?" or "A burger house is open on the next street 7/24 hours. XXL potatoes and XXL drinks." Advertisements stimulate our impulses.

External eating explains the relationship between motor impulsivity and food intake [27]. Brain imaging observations report that structures included in appetitive behaviors and reward, especially the amygdala, insula, striatum, and orbital frontal cortex, tend to be activated by both smoking cues and visual food [28]. In light of all pieces of information and increased final externality scores of our study, craving for a cigarette in heavy smokers may replace with a higher craving for food. Thus, it may end with post-cessation weight gain.

Cigarette as an old friend for a nicotine addict will not a new enemy even if it was a reason to gain weight. Thus, we do not need to find new weapons for cessation therapies. We need psychiatric support to ensure a continuous biopsychosocial approach. Maybe, we should give a specially prepared dietary list for smokers while giving cessation prescriptions.

\section{Study Limitations}

The observation was the only period of six months, and data were from smoking cessation treatment or questionnaire results, not planned to evaluate determinants of weight gain, such as daily physical activity or food calorie intake.

Acknowledgements: The authors thank all individuals support in the study.

Ethics Committee Approval: The Taksim Training and Research Hospital Clinical Research Ethics Committee reviewed and approved this study on date 13/06/2018 (Approval no: 68).

Conflict of Interest: The authors declare that there is no conflict of interest.
Financial Disclosure: No sources of funding were used to conduct this study or prepare this manuscript.

Authorship Contributions: Concept - AEK, OB; Design - AEK, OB; Supervision - AEK, OB; Data collection and/or processing - AEK, $\mathrm{OB}, \mathrm{MMB}$; Analysis and/or interpretation - $\mathrm{AEK}, \mathrm{OB}, \mathrm{MMB}$; Literature review - $A E K, O B, M M B$; Literature review - $A E K, O B, M M B$; Writing - AEK, OB, MMB; Critical review - AEK, OB, MMB.

\section{REFERENCES}

1. Peacock A, Leung J, Larney S, Colledge S, Hickman M, Rehm J, et al. Global statistics on alcohol, tobacco and illicit drug use: 2017 status report. Addiction 2018;113:1905-26. [CrossRef]

2. WHO. WHO report on the global tobacco epidemic 2017. Available at: https://www.who.int/tobacco/global_report/2017/en/. Accessed Jul 20, 2019.

3. Wack JT, Rodin J. Smoking and its effects on body weight and the systems of caloric regulation. Am J Clin Nutr 1982;35:366-80. [CrossRef]

4. Williamson DF, Madans J, Anda RF, Kleinman JC, Giovino GA, Byers T. Smoking cessation and severity of weight gain in a national cohort. $\mathrm{N}$ Engl J Med 1991;324:739-45. [CrossRef]

5. Borrelli B, Mermelstein R. The role of weight concern and self-efficacy in smoking cessation and weight gain among smokers in a clinic-based cessation program. Addict Behav 1998;23:609-22. [CrossRef]

6. Jeffery RW, Hennrikus DJ, Lando HA, Murray DM, Liu JW. Reconciling conflicting findings regarding postcessation weight concerns and success in smoking cessation. Health Psychol 2000;19:242-6. [CrossRef]

7. Osler M, Prescott E, Godtfredsen N, Hein HO, Schnohr P. Gender and determinants of smoking cessation: a longitudinal study. Prev Med 1999;29:57-62. [CrossRef]

8. John U, Hanke M, Rumpf HJ, Thyrian JR. Smoking status, cigarettes per day, and their relationship to overweight and obesity among former and current smokers in a national adult general population sample. Int J Obes (Lond) 2005;29:1289-94. [CrossRef]

9. Pankova A, Kralikova E, Zvolska K, Stepankova L, Blaha M, Ovesna $\mathrm{P}$, et al. Early weight gain after stopping smoking: a predictor of overall large weight gain? A single-site retrospective cohort study. BMJ Open 2018;8:e023987. [CrossRef]

10. Asvold BO, Bjøro T, Nilsen TI, Vatten LJ. Tobacco smoking and thyroid function: a population-based study. Arch Intern Med 2007;167:142832. [CrossRef]

11. Aubin HJ, Farley A, Lycett D, Lahmek P, Aveyard P. Weight gain in smokers after quitting cigarettes: meta-analysis. BMJ 2012;345:e4439.

12. Burton P, Smit HJ, Lightowler HJ. The influence of restrained and external eating patterns on overeating. Appetite 2007;49:191-7. [CrossRef]

13. Sevincer GM, Konuk N. Emotional eating. Journal of Mood Disorders 2013;3:171-8. [CrossRef]

14. Van Strien T, Frijters JE, Bergers GP, Defares PB. The Dutch Eating Behavior Questionnaire (DEBQ) for Assessment of Restrained, Emotional, and External Eating Behavior. International Journal of Eating Disorders 1986;5:295-315. [CrossRef]

15. Bozan N, Bas M, Asci FH. Psychometric properties of Turkish version of Dutch Eating Behaviour Questionnaire (DEBQ). A preliminary results. Appetite 2011;56:564-6. [CrossRef]

16. Uysal MA, Kadakal F, Karşidağ C, Bayram NG, Uysal O, Yilmaz V. Fagerstrom test for nicotine dependence: reliability in a Turkish sample and factor analysis. Tuberk Toraks 2004;52:115-21.

17. Kmetova A, Kralikova E, Stepankova L, Zvolska K, Blaha M, Sticha M, 
et al. Factors associated with weight changes in successful quitters participating in a smoking cessation program. Addict Behav 2014;39:239-45.

18. Komiyama M, Wada H, Ura S, Yamakage H, Satoh-Asahara N, Shimatsu A, et al. Analysis of factors that determine weight gain during smoking cessation therapy. PLoS One 2013;8:e72010. [CrossRef]

19. Shimokata H, Muller DC, Andres R. Studies in the distribution of body fat. III. Effects of cigarette smoking. JAMA 1989;261:1169-73.

20. Chiolero A, Faeh D, Paccaud F, Cornuz J. Consequences of smoking for body weight, body fat distribution, and insulin resistance. Am J Clin Nutr 2008;87:801-9. [CrossRef]

21. Filozof C, Fernández Pinilla MC, Fernández-Cruz A. Smoking cessation and weight gain. Obes Rev 2004;5:95-103. [CrossRef]

22. Jo YH, Talmage DA, Role LW. Nicotinic receptor-mediated effects on appetite and food intake. J Neurobiol 2002;53:618-32. [CrossRef]

23. van Strien T, Herman CP, Verheijden MW. Eating style, overeating, and overweight in a representative Dutch sample. Does external eating play a role?. Appetite 2009;52:380-7. [CrossRef]

24. Konttinen H, Llewellyn C, Silventoinen K, Joensuu A, Männistö S, Salomaa V, et al. Genetic predisposition to obesity, restrained eating and changes in body weight: a population-based prospective study. Int J Obes (Lond) 2018;42:858-65. [CrossRef]

25. Ogden J. Effects of smoking cessation, restrained eating, and motivational states on food intake in the laboratory. Health Psychol 1994;13:114-21. [CrossRef]

26. Ogden J, Fox P. Examination of the use of smoking for weight control in restrained and unrestrained eaters. Int J Eat Disord 1994;16:177-85.

27. Kakoschke N, Kemps E, Tiggemann M. External eating mediates the relationship between impulsivity and unhealthy food intake. Physiol Behav 2015;147:117-21. [CrossRef]

28. Tang DW, Fellows LK, Small DM, Dagher A. Food and drug cues activate similar brain regions: a meta-analysis of functional MRI studies. Physiol Behav 2012;106:317-24. [CrossRef] 